\title{
Contextos domésticos no sítio arqueológico do Porto, Santarém, Brasil, identificados com o auxílio da geofísica por meio do método GPR Domestic contexts at the archaeological site of Porto, Santarém, Brazil, identified with the support of geophysics by means of the GPR method
}

\author{
Denise Maria Cavalcante Gomes', José Gouvêa Luiz"ll \\ Universidade Federal do Rio de Janeiro/Museu Nacional. Rio de Janeiro, Rio de Janeiro, Brasil \\ "Universidade Federal do Pará. Belém, Pará, Brasil
}

\begin{abstract}
Resumo: $\bigcirc$ artigo discute a aplicação sistemática do método geofísico Radar de Penetração no Solo (GPR) na prospecção arqueológica intrassítio realizada no sítio do Porto (PA 00788), localizado em área urbana, no município de Santarém, Pará. O método indicou diferentes tipos de anomalia, testados por meio de escavações. Os resultados apontaram para a existência de feições antrópicas para deposição de lixo e de áreas para a produção de artefatos líticos, além de um enterramento secundário em urna cerâmica, o que permitiu ampliar o conhecimento sobre os contextos domésticos da cultura Santarém (1000-1600 A.D.)
\end{abstract}

Palavras-chave: Arqueologia. Arqueologia urbana. Geofísica. GPR. Santarém.

\begin{abstract}
The article discusses the systematic use of the geophysical method Ground-Penetrating Radar (GPR) in archaeological intra-site surveys conducted at Port site (PA 00788), located in urban area in the municipality of Santarém, State of Pará, Brazil. The method indicated different types of anomalies which have been tested by excavations. The results pointed to the existence of anthropogenic features for deposition of trash and activity areas for production of lithic artifacts, besides a secondary burial in ceramic urn, improving the knowledge on domestic contexts of the Santarém culture (1000-1600 A.D.).
\end{abstract}

Keywords: Archaeology. Urban archaeology. Geophysics. GPR. Santarém.

GOMES, Denise Maria Cavalcante; LUIZ, José Gouvêa. Contextos domésticos do sítio do Porto, Santarém, Pará, identificados a partir de contribuição da geofísica por meio do método GPR. Boletim do Museu Paraense Emílio Goeldi. Ciências Humanas, v. 8, n. 3, p. 639-656, set.-dez. 2013.

Autor para correspondência: Denise Maria Cavalcante Gomes. Universidade Federal do Rio de Janeiro. Museu Nacional. Departamento de Antropologia. Quinta da Boa Vista, s/n - São Cristóvão. Rio de Janeiro, RJ, Brasil. CEP 20940-040 (denisecavalcante@yahoo.com). Recebido em 04/12/2012

Aprovado em 14/10/2013

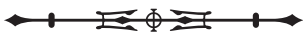




\section{INTRODUÇÃO}

A mudança de foco do estudo dos artefatos museológicos para os assentamentos e para as paisagens tem se dado em época recente na região de Santarém, Pará, a partir das primeiras pesquisas sistemáticas na área, ocorridas no final da década de 1980. Uma das preocupações dos projetos atuais, ao lado da construção de uma cronologia, consiste em detalhar os contextos de uso dos objetos cerâmicos. Esta é uma tarefa importante, uma vez que Santarém se constituiu como uma das regiões de destaque para a discussão das hipóteses de emergência de sociedades complexas na arqueologia amazônica. Essas sociedades foram descritas na literatura como formações regionais, hierárquicas, com grande densidade populacional e centralização política. Nesse sentido, para se testar tais proposições é de fundamental importância saber o tamanho e a forma de organização das aldeias, além de aspectos relativos ao uso dos artefatos.

Os relatos etno-históricos tiveram um papel relevante na constituição de uma imagem emblemática das populações indígenas que habitaram a região de Santarém à época da conquista europeia. Entre os séculos XVI e XVII, esta área foi referida pelos cronistas como sendo densamente povoada, com extensas aldeias, formas hierárquicas de chefia, rituais coletivos envolvendo consumo de bebidas, além de práticas de mumificação, que valorizavam seus ancestrais (Carvajal, 1941; Rojas, 1941; Acuña, 1941; Heriarte, 1874; Bettendorf, 1910; Daniel, 1976). A cultura material foi descrita como sendo elaborada com a existência de ídolos, mas não há maiores detalhes sobre a produção de artefatos, suas funções e usos no espaço da aldeia.

No século XVII, à época do estabelecimento da missão jesuíta, os cronistas mencionam a presença dos Tapajó, bem como de outros grupos, a exemplo dos Marautus, Caguanas e Orurucus, Carossirazes e Quaxinazes, vivendo na região do rio Tapajós (Heriarte, 1874; Bettendorf, 1910). A correlação étnica da cerâmica arqueológica com os Tapajó, entretanto, foi feita somente no século XIX pelo naturalista Barbosa Rodrigues (1875). A partir daí, esta correlação manteve-se, tendo sido cristalizada por Curt Nimuendajú, responsável pela elaboração de um perfil etnográfico do grupo a partir das crônicas etno-históricas e dos vestígios arqueológicos descobertos por ele nos anos 1920 (Nimuendajú, 1949).

No momento em que a pesquisa arqueológica na Amazônia se move em diferentes direções, muitas delas voltadas para o conhecimento do modo de vida das antigas populações indígenas (Heckenberger e Neves, 2009), é importante reconhecer a necessidade de trabalhos que consigam desvendar aspectos relativos às práticas cotidianas dos grupos indígenas do passado pré-colonial. Para tanto, torna-se imprescindível, no caso de Santarém, conhecer não só os contextos rituais associados à cerâmica elaborada, bem como aqueles relativos às práticas cotidianas de subsistência no espaço da aldeia.

As pesquisas arqueológicas aqui apresentadas foram realizadas no sítio do Porto (PA 00788), na área de expansão do Campus Tapajós, da Universidade Federal do Oeste do Pará (UFOPA), e tiveram como propósito investigar os contextos da cerâmica Santarém, visando a detecção de feições e áreas de atividade das comunidades pretéritas que lá habitaram. Nesse sentido, a prospecção geofísica intrassítio, por meio do método Radar de Penetração no Solo (GPR), buscou identificar anomalias no subsolo, que poderiam estar associadas a estruturas ou artefatos de interesse arqueológico.

Este artigo enfatiza a contribuição metodológica da geofísica aplicada à arqueologia no conhecimento dos contextos domésticos da cultura Santarém, que revelaram a existência de feições de deposição de lixo comum, áreas de atividade relacionadas à produção de artefatos líticos e padrões funerários de enterramento secundário no espaço habitacional.

\section{A ÁREA DE PESQUISA}

O levantamento arqueológico realizado pelo etnólogo alemão Curt Nimuendajú (Nimuendajú, 1949; Stenborg,

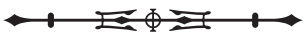


2004) na região de Santarém, entre 1923 e 1926, deixou como legado a identificação de 140 sítios, a maior parte deles de terra preta e associada à cultura Santarém. Além disso, Nimuendajú contribuiu para estabelecer os limites gerais da cultura Santarém, que se estendem em uma área com cerca de $20.000 \mathrm{~km}^{2}$, tendo ao norte os arredores de Almerim, no rio Amazonas, a leste a foz do Xingu, a oeste a região do rio Trombetas e ao sul a comunidade de Boim, situada na margem esquerda do Tapajós, distante cerca de $100 \mathrm{~km}$ com relação a Santarém (Palmatary, 1960).

Segundo Nimuendajú (1949), o sítio Aldeia (PA 01037), situado no bairro homônimo na cidade de Santarém, era o mais extenso dos sítios de terra preta por ele identificados. Foi encontrado a partir de valas abertas após chuvas torrenciais, que expuseram depósitos de cerâmica elaborada. $\bigcirc$ atual sítio do Porto (PA 00788), situado na antiga praia da Vera Paz, também foi objeto de intervenções realizadas pelo referido etnólogo (Stenborg, 2004). Hoje, ambos os sítios, localizados em área urbana, vêm sendo objeto de pesquisas sistemáticas.

Vários autores divulgaram os resultados das pesquisas de Nimuendajú, entre eles Linné (1928), Nordenskiöld (1930) e Métraux (1930), fazendo com que a cerâmica de Santarém tivesse visibilidade internacional. Diversas coleções foram constituídas em museus do mundo. Estas coleções começaram a ser estudadas a partir da década de 1930, sendo o primeiro um estudo tipológico de Palmatary (1939). Depois disso, seguiramse diversos outros estudos de coleções, em uma tradição que permanece até os dias atuais (Barata, 1950, 1951, 1953a, 1953b; Palmatary, 1960; Corrêa, 1965; MacDonald, 1972; Roosevelt, 1988; Guapindaia, 1993; Gomes, 2001, 2002, 2006, 2007, 2010, 2012).
Independente do enfoque destas análises, o que se destaca nos acervos não são os artefatos de uso doméstico, mas os objetos cerimoniais selecionados a partir de suas qualidades estéticas, tais como estatuetas antropomorfas masculinas e femininas e vasos de morfologia e decoração elaboradas como representações icônicas de animais e seres em transformação. Entretanto, como estes artefatos rituais encontrados nas coleções museológicas em diversos países do mundo foram recuperados principalmente no sítio Aldeia por meio de saques e escavações ilegais realizadas por leigos, seus contextos arqueológicos permaneceram por muito tempo desconhecidos.

No final da década de 1980, com o início das escavações sistemáticas realizadas por Roosevelt no sítio do Porto (PA 00788), orientadas a partir de indicações de anomalias geofísicas, foi possível documentar arqueologicamente alguns dos contextos cerimoniais, especialmente as estruturas referidas como 'bolsões', que constituem buracos intencionalmente cavados para a deposição de artefatos cerimoniais, carvão e ossos de animais (Roosevelt, 1999, 2007, 2009; Quinn, 2004). Já no sítio Aldeia (PA 01037), as primeiras escavações sistemáticas foram realizadas entre 2006 e 2010, sendo associadas a projetos de pesquisa básica, coordenados por Gomes (2010)1. Esses projetos não só confirmaram o padrão relativo à cerâmica cerimonial, como também revelaram outras formas de deposição artefatual, tais como a queima intencional da cerâmica ritual.

O sítio do Porto (PA 00788), localizado no bairro de Salé, é hoje ocupado pelas instalações da empresa Cargill. O terreno pertence à Companhia das Docas do Pará, sendo parte dele também situada em área do Campus Tapajós/UFOPA (Figura 1). O sítio do Porto constitui parte do conjunto arqueológico de ocupações urbanas em

\footnotetext{
1 Ver também GOMES, Denise Maria Cavalcante. Identificação de sítios arqueológicos da cultura Santarém na área central da cidade de Santarém, PA. Relatório Final apresentado ao Instituto do Patrimônio Histórico e Artístico Nacional (IPHAN). São Paulo, 2006; e GOMES, Denise Maria Cavalcante. Relatório da etapa de campo relativa à escavação do Sítio Aldeia - Santarém, PA. Projeto de Pós-Doutorado: Cronologia e Contexto Cerimonial da Cultura Santarém. Relatório parcial apresentado ao Instituto de Patrimônio Histórico e Artístico Nacional (IPHAN). São Paulo, 2008.
}

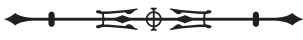




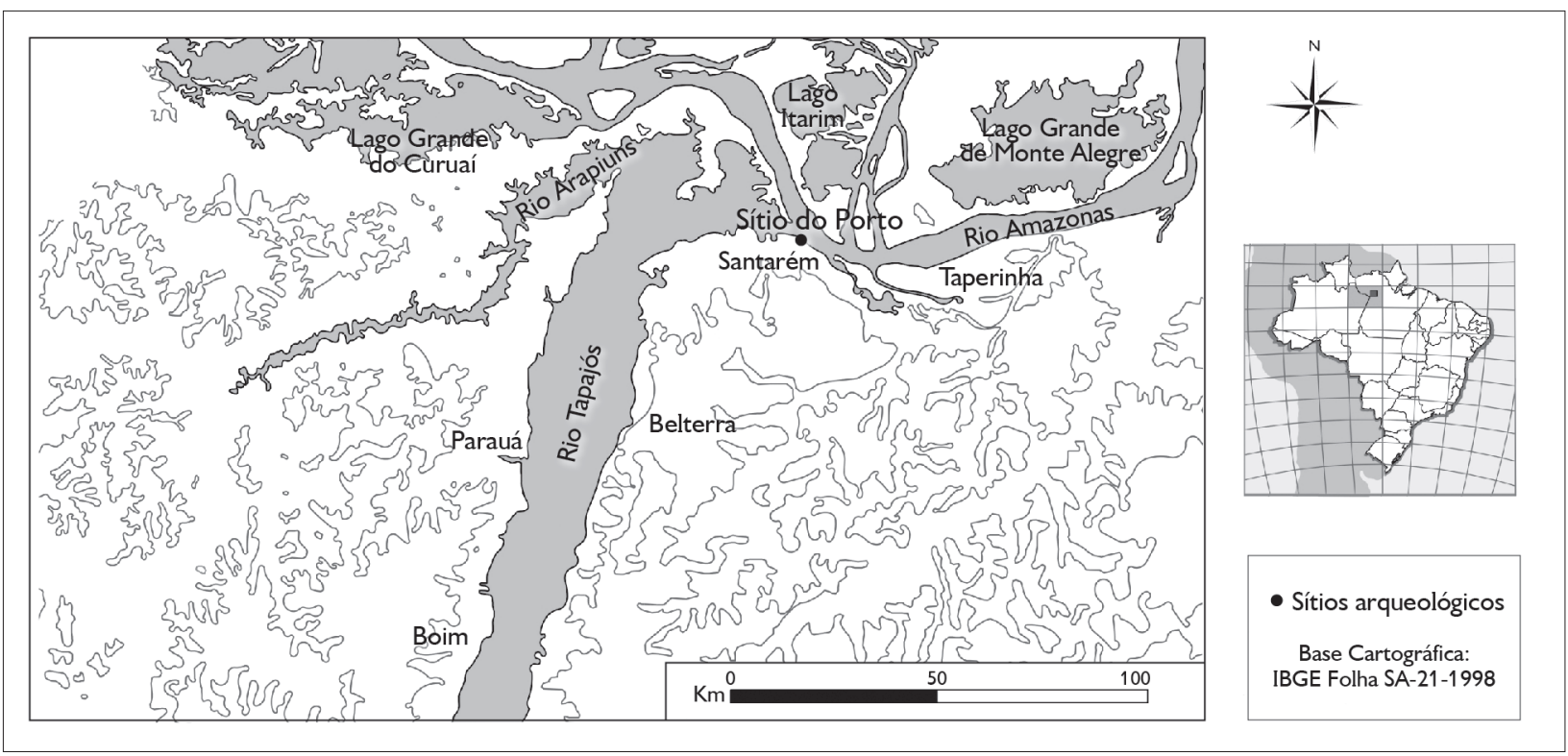

Figura 1. Mapa da região de Santarém com indicação do sítio do Porto.

Santarém, com cerca de $5 \mathrm{~km}$ de extensão, tendo sido objeto de escavações realizadas por Curt Nimuendajú na década de 1920. Nimuendajú (2004, p. 131) descreve na área da antiga praia Vera Paz a ocorrência de habitações, vestígios superficiais de cerâmica associada aos Tapajó, além de fragmentos de uma cerâmica diferente, pintada de vermelho e branco, artefatos líticos, vértebras de peixes, cascos de tartaruga e ossos de animais, contidos na parte média e inferior de um estrato com 1,40 m de profundidade, o que levou o autor a considerar uma segunda ocupação, de outro grupo anterior aos Tapajó.

A descrição de Nimuendajú está de acordo com os resultados das escavações realizadas por Roosevelt e colaboradores, que detectaram estruturas habitacionais (plataformas de formato linear, interpretadas como fundações de casas), áreas de atividades relativas a cerimônias e à produção de artefatos, bem como evidenciaram os referidos bolsões cerimoniais contendo cerâmica Santarém. Obtiveram, ainda, uma cronologia com datações que vão desde o período formativo até o século XV d.C. (Roosevelt, 1999, 2009; Quinn, 2004). Há notícias de outras escavações realizadas no sítio do Porto, a partir de 2007, sob a coordenação de Denise Schaan².

Neste sítio, o setor ocupado pelo Campus Tapajós/UFOPA foi objeto de pesquisas arqueológicas coordenadas por Denise Gomes, realizadas em 2011 e orientadas a partir de prospecção geofísica ${ }^{3}$. A área submetida à prospecção e escavação arqueológica foi denominada de Área 1, subdividida em Área 1A. Esta que possui terra preta arqueológica variando de acordo com a tabela Munsel entre 7.5 YR 2.5/1 (black) até 7.5 YR 3/2 (dark brown), com vestígios líticos (lascas, micro-lascas e afiadores) e cerâmicos em superfície associados à ocupação Santarém tardia - está assentada num terreno de relevo colinar, cujas cotas altimétricas variam entre 25 e 21 m (Figura 2), medindo um total de

\footnotetext{
2 Ver SCHAAN, Denise Pahl. Relatório final de salvamento do sítio PA-ST-43: Porto de Santarém. Belém: UFPA, 2010.

3 Ver GOMES, Denise Maria Cavalcante; LUIZ, José Gouvêa. Primeiro relatório do Projeto Gerenciamento do patrimônio arqueológico: prospecção e resgate na área de influência direta da construção de diversas estruturas no Campus Tapajós, da UFOPA. Relatório apresentado ao IPHAN. Santarém, 2011.
}

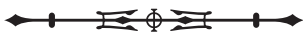



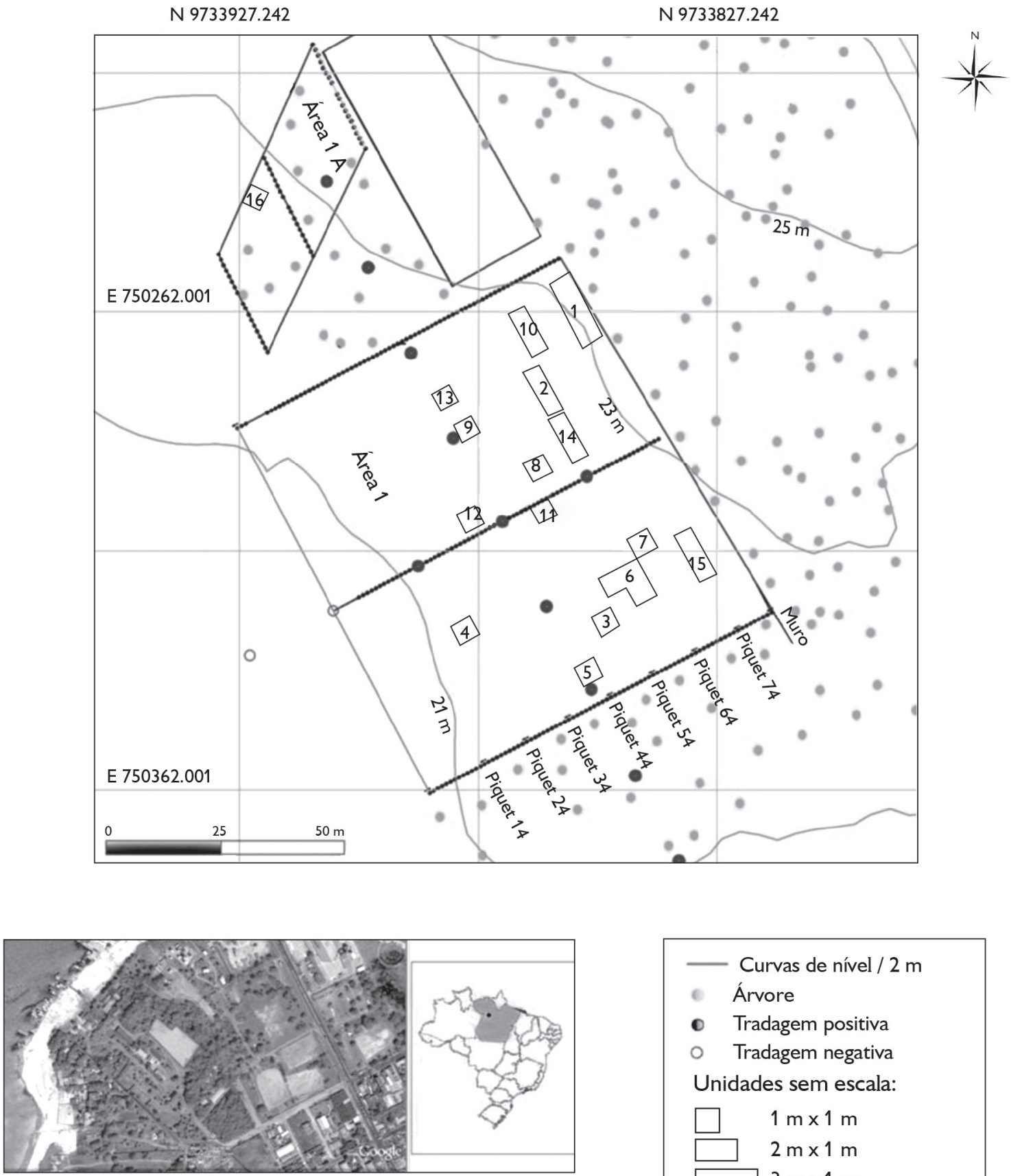

Área de Levantamento, Campus Tapajós - UFOPA Santarém, PA

\begin{tabular}{l} 
Curvas de nível / $2 \mathrm{~m}$ \\
Árvore \\
Tradagem positiva \\
Tradagem negativa \\
Unidades sem escala: \\
$\begin{array}{l}\square \mathrm{m} \times 1 \mathrm{~m} \\
\square \quad 2 \mathrm{~m} \times 1 \mathrm{~m} \\
\square \quad 3 \mathrm{~m} \times 1 \mathrm{~m} \\
\square \quad 2 \mathrm{~m} \times 1 \mathrm{~m}+1 \mathrm{~m} \times 1 \mathrm{~m}\end{array}$ \\
\hline
\end{tabular}

Figura 2. Mapa topográfico do sítio do Porto, setor do Campus Tapajós, UFOPA.

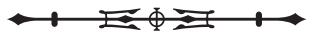


$24.400 \mathrm{~m}^{2}$. Ela dista $200 \mathrm{~m}$ das margens do rio Tapajós, tendo sido anteriormente ocupada por um lixão e depois por um campo de futebol, o que causou impactos no registro arqueológico. Estima-se que cerca de $1 \mathrm{~m}$ de camada arqueológica tenha sido retirada no processo de terraplanagem do campo de futebol. Ainda assim, com o auxílio da geofísica, foi possível identificar diferentes padrões de deposição artefatual.

\section{MATERIAIS E MÉTODOS}

Na Amazônia, a geofísica tem sido aplicada como método de prospecção intrassítio especialmente em áreas de savanas ou desmatadas, uma vez que os intervalos de prospecção de superfície costumam ser bem reduzidos (cerca de $1 \mathrm{~m}$ ). Escavações orientadas a partir da identificação de anomalias geofísicas no terreno foram realizadas por Roosevelt (1991) em tesos na ilha de Marajó. As pesquisas geofísicas na ilha foram inicialmente conduzidas por José Seixas Lourenço no ano de 1977 (Alves, 1979; Alves e Lourenço, 1981).

Roosevelt e colaboradores também utilizaram a geofísica no sítio do Porto (PA 00788), em Santarém, no final da década de 1980 e em 1990, sendo estas executadas por Bruce Bevan (Quinn, 2004; Roosevelt, 2007). Diversas outras áreas no estado do Pará foram prospectadas, a exemplo do sítio Domingos, em Canaã dos Carajás, onde foram recuperadas urnas funerárias e material lítico, e do sítio Bittencourt, em Abaetetuba, revelando cerâmicas, faiança, argila queimada, carvão e artefatos de ferro, entre outras reportadas por Luiz (2010, p. 958-964). Os resultados têm sido úteis na identificação de estruturas (por exemplo, sepultamentos com acompanhamento funerário, depósitos rituais, concentrações de artefatos etc.) e outras feições bem definidas, tais como lixeiras domésticas.

Na Área 1 do Campus Tapajós, da UFOPA, correspondente ao campo de futebol, o levantamento geofísico consistiu em medidas eletromagnéticas obtidas com o GPR, realizadas ao longo de 76 linhas, com orientação SW-NE, espaçadas em $1 \mathrm{~m}$, cujo comprimento variou entre 80 e 88 m. Já na Área 1A, contígua à primeira, onde está localizado um viveiro de plantas, foram realizadas medidas em 20 linhas, com o mesmo espaçamento de $1 \mathrm{~m}$ e extensão variando de 35 a 49 m. As medidas foram realizadas com o sistema GSSI SIR-3000, usando antenas de frequência central igual a $400 \mathrm{MHz}$. O instrumento foi operado no modo tempo (sem odômetro), com o controle da posição das medidas obtido por meio de marcas inseridas no registro a intervalos de $10 \mathrm{~m}$.

As medidas realizadas com o GPR foram processadas com o programa Reflex-Win, da Sandmeier Software, a fim de conferir melhorias aos registros. O processamento envolveu basicamente os seguintes procedimentos: a) interpolação das marcas de posicionamento horizontal para a obtenção de escala horizontal uniforme; b) aplicação de filtro dewow (filtro 'passa alta') para eliminar saturação devido às grandes amplitudes das ondas aéreas e diretas; c) estabelecimento do tempo zero de registro para obtenção do nível zero de profundidade (posição da superfície do terreno); d) aplicação de ganho para compensar a atenuação do sinal; e) aplicação de filtro de remoção de background para eliminar ruídos coerentes; f) aplicação de filtro 'passa faixa' com frequências de corte de 200 e 800 MHz; g) determinação da velocidade da onda de radar para conversão de tempo em profundidade (a velocidade foi estimada em 0,09 m/ns, usando o método de superposição de hipérbole).

Os resultados obtidos ao longo das linhas revelaram imagens que correspondem a anomalias de três tipos: hipérboles, descontinuidades e vales. Na Área 1, foram identificadas anomalias em 68 linhas, com 245 posições, determinadas a partir de distâncias em metros, tomadas por meio de piquetes numerados e consideradas com potencial de análise arqueológica. Por outro lado, na Área 1A, vista como sendo de menor prioridade, devido à presença de blocos de concreções lateríticas (que também provocam anomalias), foram identificadas anomalias em 20 linhas, com 47 posições indicadas para escavações. 
A realização prévia de 15 tradagens na área de pesquisa, dispostas nos eixos $N / E$, indicou que a ocorrência de terra preta e de vestígios arqueológicos cerâmicos e líticos se dá na totalidade das Áreas 1 e $1 \mathrm{~A}$, ultrapassando o limite do campo de futebol em cerca de $40 \mathrm{~m}$ ao sul. Na Área $1 \mathrm{~A}$, à medida que se avança na direção norte, a densidade de artefatos diminui com relação à primeira e aumentam as concreções lateríticas. Por outro lado, as tradagens ao sul apresentaram grande quantidade de lixo recente (vidro, material construtivo e metais), confirmando as informações orais sobre a antiga utilização da área como lixão.

Após as tradagens, escavações foram realizadas em 17 áreas, totalizando $24 \mathrm{~m}^{2}$ investigados, em unidades com profundidades variadas, escavadas em níveis artificiais de $10 \mathrm{~cm}$. O objetivo dessas escavações foi testar amostralmente os diferentes tipos de anomalia apontados pela prospecção geofísica, a qual, conforme mencionado, permitiu uma varredura sistemática do terreno, já que as linhas de levantamento possuíam uma distância de apenas $1 \mathrm{~m}$. Os diferentes tipos de anomalia e suas combinações (vale; descontinuidade; vale com descontinuidade; hipérbole; e hipérbole com descontinuidade) foram investigados, a fim de determinar a correspondência destes padrões com a existência de estruturas e feições arqueológicas. Ao todo, 17 anomalias geofísicas foram analisadas. As dimensões das áreas de escavação variaram em função da extensão das anomalias: $1 \times 1 \mathrm{~m} ; 2 \times 2 \mathrm{~m} ; 3 \times 1 \mathrm{~m} ; 2 \times 1 \mathrm{~m}+1 \mathrm{~m}$.

\section{RESULTADOS E DISCUSSÃO}

Conforme tem sido demonstrado por vários estudos desde os anos 1940, a geofísica é capaz de fornecer informações tridimensionais sobre a camada arqueológica, permitindo orientar as escavações em torno de áreas de maior potencial de estudo, geralmente associadas a estruturas de combustão e concentrações cerâmicas, detectando ainda informações sobre a estratigrafia e a camada de ocupação (Luiz, 2010, p. 951). Deve-se ressaltar, entretanto, que as anomalias geofísicas evidenciadas nos levantamentos podem ser causadas por fontes diferentes daquelas que estão sendo procuradas. Elas podem, muitas vezes, estar associadas, especialmente na área urbana, a interferências antrópicas (camadas de aterro, artefatos metálicos, tubulações, entre outras) ou, ainda, associadas à bioturbação causada por insetos e roedores. Por esse motivo, é comum que as escavações realizadas para investigar as anomalias não encontrem artefatos arqueológicos.

Das 17 anomalias geofísicas testadas, sete apresentaram potencial arqueológico relacionado a atividades pretéritas (Tabela 1). Desse modo, foram evidenciadas feições que correspondem a comportamentos de limpeza e manutenção da aldeia, tais como lixeiras intencionalmente cavadas, fogueiras, contextos funerários, com a recuperação de uma urna, além de áreas de atividade relativas à produção de artefatos lascados, também identificadas. Nesse sentido, a adoção de uma metodologia sistemática de prospecção geofísica em linhas dispostas a intervalos de $1 \mathrm{~m}$ e a escavação de unidades de superfícies contínuas (dispostas de maneira amostral por toda a extensão do terreno, estas últimas totalizando $24 \mathrm{~m}^{2}$ ) permitiram uma boa cobertura de pesquisa.

As escavações revelaram uma camada de terra preta arqueológica pouco espessa, com profundidade variável entre 10 e $70 \mathrm{~cm}$, chegando até $110 \mathrm{~cm}$ nas áreas correspondentes às feições antrópicas, especialmente aquelas associadas a buracos intencionalmente cavados pelas populações pré-coloniais para deposição de lixo (fragmentos cerâmicos, lascas líticas, ossos de animais, carvões etc.), presentes na aldeia. Duas destas lixeiras pré-coloniais foram detectadas pelo levantamento geofísico e correspondem a anomalias descritas como vale com descontinuidade (Figuras 3, 4, 5 e 6), assinalando um buraco de terra preta, cavado em forma de vale, cuja descontinuidade se dá em relação ao solo de cor marrom amarelado e à terra preta arqueológica. As densidades máximas de artefatos líticos e cerâmicos, verificadas em todas as unidades escavadas, a cada $10 \mathrm{~cm}$, variaram entre 36 e 2497 g (lítico) e 13 e 3508 g (cerâmica). As maiores densidades estão correlacionadas a estas feições antrópicas. 
Tabela 1. Anomalias geofísicas e sua correspondência arqueológica no sítio do Porto (Campus Tapajós, UFOPA), Santarém, Pará.

\begin{tabular}{|c|c|c|c|}
\hline $\begin{array}{c}\text { Unidade } \\
\text { de escavação }\end{array}$ & $\begin{array}{l}\text { Anomalia } \\
\text { geofísica }\end{array}$ & $\begin{array}{l}\text { Descrição do } \\
\text { conteúdo arqueológico }\end{array}$ & $\begin{array}{l}\text { Interpretação } \\
\text { da anomalia }\end{array}$ \\
\hline $\begin{array}{l}1-\mathrm{N} 1029 \text { E1034, } \\
\text { N1030 E1034, } \\
\text { N1031E1034 }\end{array}$ & $\begin{array}{c}\text { Descontinuidade } \\
\text { com hipérbole } \\
\text { (linha } 75 \text {, entre } 73 \text { e } 76 \text { m) }\end{array}$ & $\begin{array}{c}\text { Baixa densidade de vestígios líticos lascados, } \\
\text { pequenas lascas e microlascas em silexito, } \\
\text { calibradores com sulcos e fragmentos cerâmicos. } \\
\text { Buracos de animais }\end{array}$ & $\begin{array}{l}\text { Anomalia geofísica } \\
\text { associada à bioturbação }\end{array}$ \\
\hline $\begin{array}{l}2 \text { - N1021 E1020, } \\
\text { N1022 E1020 }\end{array}$ & $\begin{array}{l}\text { Vale com descontinuidade } \\
\text { (linha 61, entre } 65 \text { e } 67 \text { m) }\end{array}$ & $\begin{array}{c}\text { Abundantes fragmentos cerâmicos de estilo } \\
\text { Santarém, microlascas e calibradores contidos } \\
\text { num bolsão de terra preta }\end{array}$ & $\begin{array}{l}\text { Feição antrópica } \\
\text { correspondente a uma lixeira } \\
\text { intencionalmente cavada }\end{array}$ \\
\hline 3 - N970 E1009 & $\begin{array}{c}\text { Hipérbole } \\
\text { (linha 50, entre } 14 \text { e } 15 \text { m) }\end{array}$ & $\begin{array}{c}\text { Material construtivo, plástico, vidro e arame } \\
\text { nos primeiros } 20 \mathrm{~cm} \text {. Abaixo desta camada, há } \\
\text { grande densidade de vestígios líticos e pequenos } \\
\text { fragmentos cerâmicos }\end{array}$ & $\begin{array}{l}\text { Anomalia geofísica associada } \\
\text { à presença de arame na } \\
\text { camada de aterro }\end{array}$ \\
\hline 4 - N982 E983 & $\begin{array}{c}\text { Hipérbole } \\
\text { (linha 23, entre } 26 \text { e } 27 \text { m) }\end{array}$ & $\begin{array}{l}\text { Camada superior, com material construtivo e } \\
\text { lixo recente, com baixa densidade de artefatos } \\
\text { e cerâmica muito fragmentada. Grande } \\
\text { concentração de laterita a partir de } 80 \mathrm{~cm}\end{array}$ & $\begin{array}{l}\text { Anomalia geofísica } \\
\text { relacionada à camada } \\
\text { de aterro }\end{array}$ \\
\hline 5 - N960 E1001 & $\begin{array}{l}\text { Descontinuidade } \\
\text { (linha 42, entre } 4 \text { e } 5 \text { m) }\end{array}$ & $\begin{array}{c}\text { Camada superior de aterro, com plástico, } \\
\text { vidro, vergalhão de ferro, material construtivo. } \\
\text { Camada de terra preta a partir dos } 40 \mathrm{~cm} \text {, } \\
\text { com grande concentração de lítico lascado e } \\
\text { calibradores }\end{array}$ & $\begin{array}{l}\text { Anomalia geofísica } \\
\text { relacionada a um vergalhão de } \\
\text { ferro na camada de aterro }\end{array}$ \\
\hline $\begin{array}{l}6 \text { - N978 E1020, } \\
\text { N979E1020 }\end{array}$ & $\begin{array}{l}\text { Vale com descontinuidade } \\
\text { (linha 61, entre } 22,5 \text { e } 24 \text { m) }\end{array}$ & $\begin{array}{c}\text { Fragmentos cerâmicos, lascas, afiadores com } \\
\text { sulcos, ossos de peixe-boi contidos num bolsão } \\
\text { de terra preta }\end{array}$ & $\begin{array}{l}\text { Feição antrópica } \\
\text { correspondente a uma lixeira } \\
\text { intencionalmente cavada }\end{array}$ \\
\hline 6 - N979 E1029 & $\begin{array}{c}\text { Descontinuidade } \\
\text { (linha 60, entre } 23 \text { e } 24 \text { m) }\end{array}$ & $\begin{array}{l}\text { Urna funerária com sedimento no interior e } \\
\text { microfragmentos ósseos }\end{array}$ & Artefato inteiro \\
\hline 7 - N980 E1022 & $\begin{array}{c}\text { Descontinuidade com } \\
\text { hipérbole } \\
\text { (linha 63, entre } 24 \text { e } 25 \text { m) }\end{array}$ & $\begin{array}{l}\text { Baixa densidade de artefatos cerâmicos e líticos. } \\
\text { Concentração cerâmica aos } 40 \mathrm{~cm}\end{array}$ & Concentração cerâmica \\
\hline 8 - N1005 E1011 & $\begin{array}{c}\text { Hipérbole } \\
\text { (linha 52, entre } 49 \text { e } 50 \text { m) }\end{array}$ & $\begin{array}{c}\text { Fogueira com abundante carvão entre } \\
10-20 \mathrm{~cm} \text {. Cerâmica com elementos } \\
\text { diagnósticos Santarém, lasca em silexito } \\
\text { e artefato lítico sobre núcleo }\end{array}$ & Fogueira e artefatos \\
\hline 9 - N1019 E1003 & $\begin{array}{c}\text { Hipérbole } \\
\text { (linha 43, entre } 63 \text { e } 64 \text { m) }\end{array}$ & $\begin{array}{l}\text { Camada de aterro com material construtivo e } \\
\text { pregos, microlascas e fragmentos cerâmicos }\end{array}$ & $\begin{array}{l}\text { Anomalia geofísica associada } \\
\text { aos pregos de metal }\end{array}$ \\
\hline
\end{tabular}

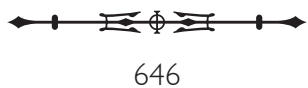


Tabela 1.

(Conclusão)

\begin{tabular}{|c|c|c|c|}
\hline $\begin{array}{c}\text { Unidade } \\
\text { de escavação }\end{array}$ & $\begin{array}{l}\text { Anomalia } \\
\text { geofísica }\end{array}$ & $\begin{array}{c}\text { Descrição do } \\
\text { conteúdo arqueológico }\end{array}$ & $\begin{array}{l}\text { Interpretação } \\
\text { da anomalia }\end{array}$ \\
\hline $\begin{array}{l}10 \text { - N1029 E1023, } \\
\text { N1028 E1023 }\end{array}$ & $\begin{array}{l}\text { Vale com descontinuidade } \\
\text { (linha 64, entre } 71,5 \text { e } 74 \text { m) }\end{array}$ & $\begin{array}{l}\text { Camada residual de terra preta com } 20 \mathrm{~cm} \\
\text { e baixa densidade de vestígios. Sinais de } \\
\text { bioturbação nas camadas mais profundas }\end{array}$ & $\begin{array}{l}\text { Anomalia geofísica } \\
\text { sem explicação }\end{array}$ \\
\hline 11 - N996 E1008 & $\begin{array}{c}\text { Hipérbole } \\
\text { (linha 49, entre } 41 \text { e } 42 \text { m) }\end{array}$ & $\begin{array}{l}\text { Camada de aterro até } 20 \mathrm{~cm} \text {, com vidro, } \\
\text { material construtivo e pregos, contendo ainda } \\
\text { grande densidade de calibradores }\end{array}$ & $\begin{array}{l}\text { Concentração } \\
\text { de calibradores }\end{array}$ \\
\hline 12 - N1002 E994 & $\begin{array}{c}\text { Descontinuidade } \\
\text { (linha 35, entre } 46 \text { e } 47 \text { m) }\end{array}$ & $\begin{array}{l}\text { Cerâmica bastante fragmentada, lascas líticas } \\
\text { e calibrador de laterita. Aos } 30 \mathrm{~cm} \text {, há grande } \\
\text { concentração de rochas }\end{array}$ & $\begin{array}{l}\text { Anomalia geofísica relacionada } \\
\text { à concentração de rochas }\end{array}$ \\
\hline 13 - N1027 E1001 & $\begin{array}{c}\text { Descontinuidade } \\
\text { (linha 42, entre } 71 \text { e } 72 \text { m) }\end{array}$ & $\begin{array}{c}\text { Baixa densidade de artefatos líticos e cerâmicos } \\
\text { fragmentados misturados a material construtivo. } \\
\text { Entre } 50 \mathrm{~cm} \text { e } 80 \mathrm{~cm} \text {, há grande concentração } \\
\text { de laterita }\end{array}$ & $\begin{array}{l}\text { Anomalia geofísica associada } \\
\text { ao afloramento de laterita }\end{array}$ \\
\hline $\begin{array}{l}14 \text { - N105 E1020, } \\
\text { N1016 E1020 }\end{array}$ & $\begin{array}{c}\text { Descontinuidade } \\
\text { (linha 61, entre } 59 \text { e } 61 \text { m) }\end{array}$ & $\begin{array}{l}\text { Grande densidade de lítico lascado (lascas e } \\
\text { microlascas) em silexito nos primeiros } 30 \mathrm{~cm}\end{array}$ & $\begin{array}{c}\text { Área de atividade } \\
\text { de lascamento e produção } \\
\text { de artefatos }\end{array}$ \\
\hline $\begin{array}{l}15 \text { - N978 E1031 } \\
\text { N979 E1031 }\end{array}$ & $\begin{array}{c}\text { Descontinuidade } \\
\text { (linha } 73 \text {, entre } 21 \text { e } 24 \text { m) }\end{array}$ & $\begin{array}{c}\text { Camada de terra preta com } 40 \mathrm{~cm} \text {, contendo } \\
\text { artefatos líticos e cerâmica fragmentada. } \\
\text { Presença de formigueiros com até } 70 \mathrm{~cm}\end{array}$ & $\begin{array}{l}\text { Anomalia geofísica associada } \\
\text { à bioturbação }\end{array}$ \\
\hline 16 - N1000 E1000 & $\begin{array}{l}\text { Descontinuidade } \\
\text { (Área } 1 \mathrm{~A}, \text { linha } 2, \\
\text { entre } 9 \text { e } 10 \mathrm{~m} \text { ) }\end{array}$ & $\begin{array}{l}\text { Camada de aterro de } 30 \mathrm{~cm} \text {, com laterita, } \\
\text { material construtivo, vidro e raros fragmentos } \\
\text { cerâmicos e lascas líticas. Entre } 40 \mathrm{~cm} \text { e } 80 \mathrm{~cm} \text {, } \\
\text { ocorre terra preta com lascas e fragmentos } \\
\text { cerâmicos. Entre } 80 \mathrm{~cm} \text { e } 100 \mathrm{~cm} \text {, há } \\
\text { afloramento laterítico }\end{array}$ & $\begin{array}{c}\text { Anomalia geofísica } \\
\text { correspondente à } \\
\text { descontinuidade da camada } \\
\text { arqueológica, situada entre } \\
\text { o aterro e a camada laterítica }\end{array}$ \\
\hline
\end{tabular}

Especialmente nessas feições, foram encontradas cerâmicas com elementos diagnósticos que podem ser correlacionados à ocupação da fase Santarém tardia (1000-1600 A.D.) (Gomes, 2001, 2002, 2010; Guapindaia, 1993; Quinn, 2004). A cerâmica, em geral, está bastante fragmentada, sendo esta uma característica associada aos processos formativos culturais do sítio e não a qualquer evento recente. Ela possui paredes finas (entre 0,5 e $1 \mathrm{~cm}$ ), cauixi e caco moído como antiplástico, decoração incisa e modelada, sobressaindo a pintura vermelha como forma de decoração. Ocorrem, ainda, alguns fragmentos com ponteado, bem como elementos decorativos aplicados. Em uma dessas feições escavadas, foram registrados fragmentos de estatuetas humanas, com detalhes típicos da cerâmica Santarém, o que não deixa dúvidas sobre o complexo cultural em questão.

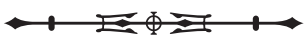




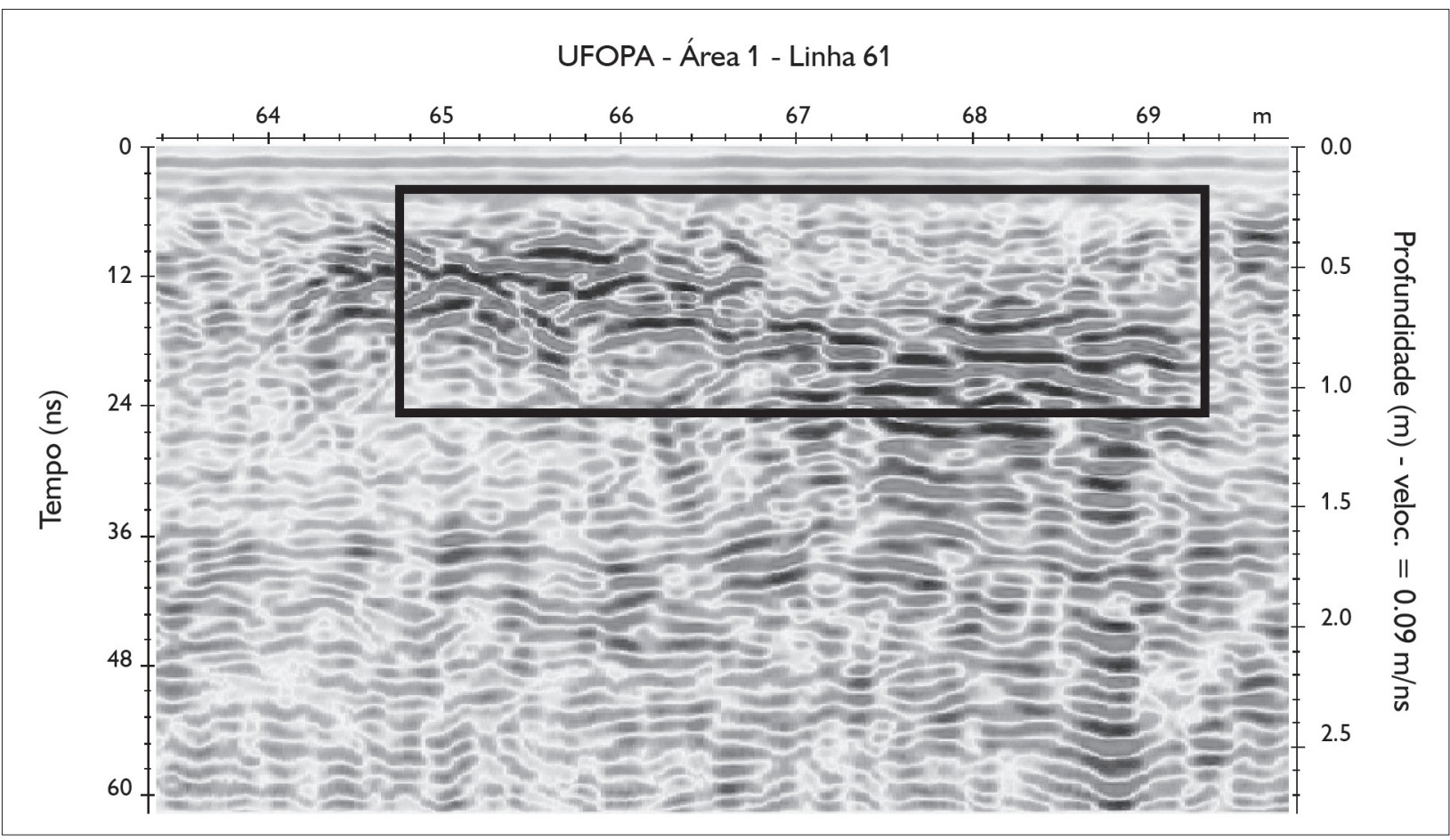

Figura 3. Imagem da linha 61, entre 65-67 m, com anomalia em forma de vale com descontinuidade, destacada pelo retângulo.

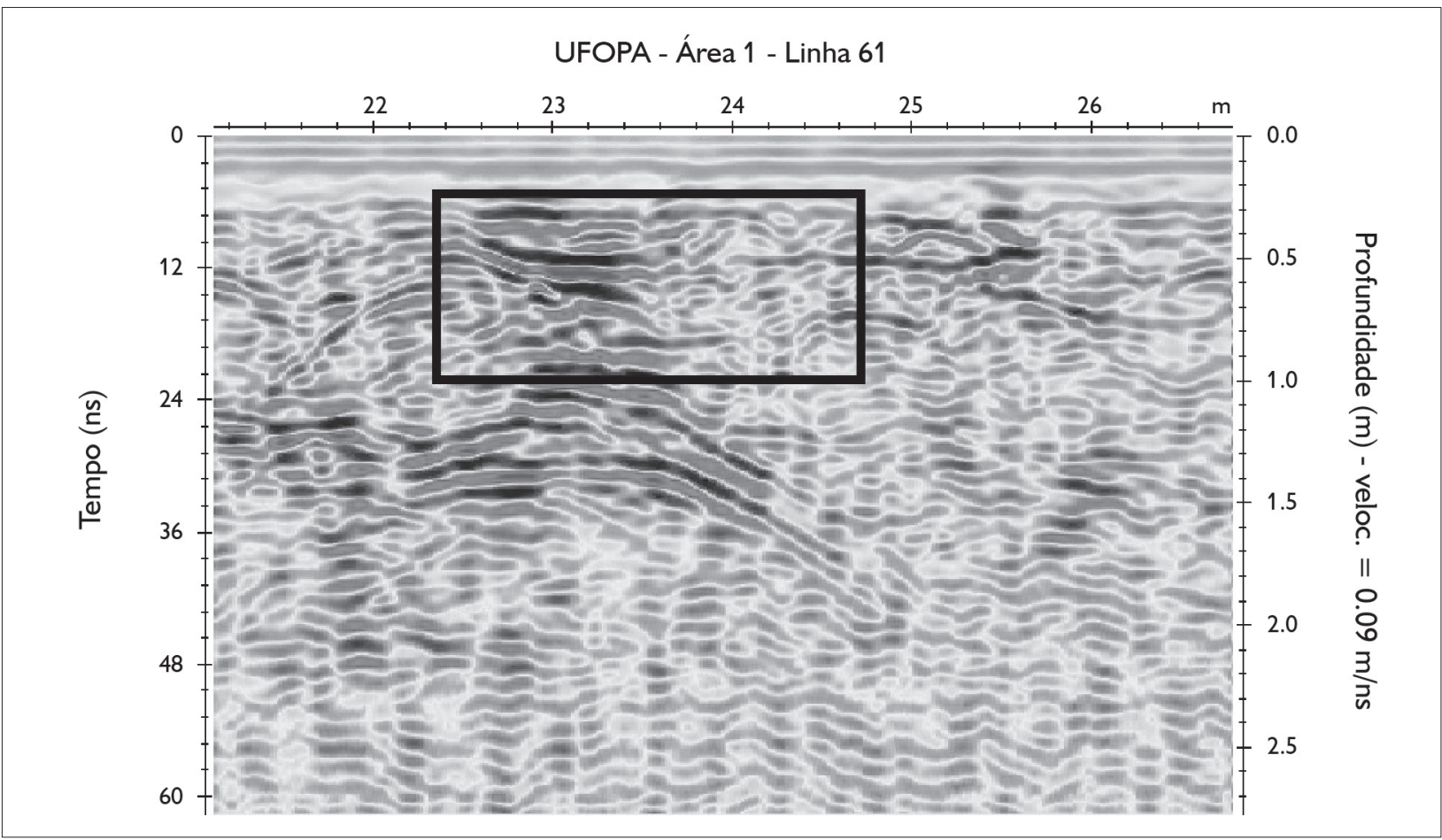

Figura 4. Imagem da linha 61, entre 22-24 m, com anomalia em forma de vale com descontinuidade, destacada pelo retângulo.

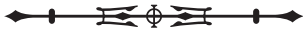




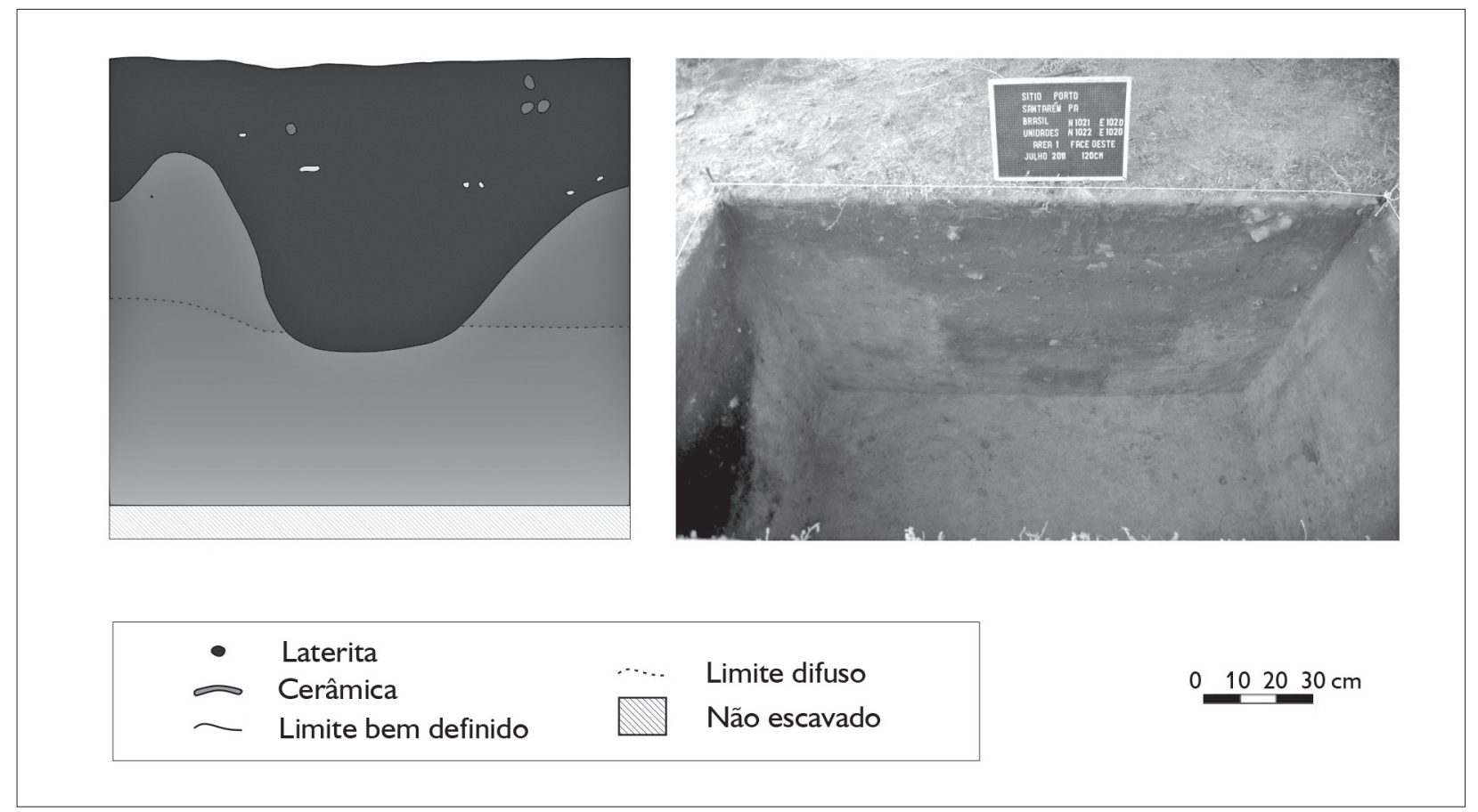

Figura 5. Desenho e foto do perfil oeste da unidade 2 - N1021 E1020, N1022 E1020, mostrando a feição em forma de vale com descontinuidade, evidenciada na Figura 3.

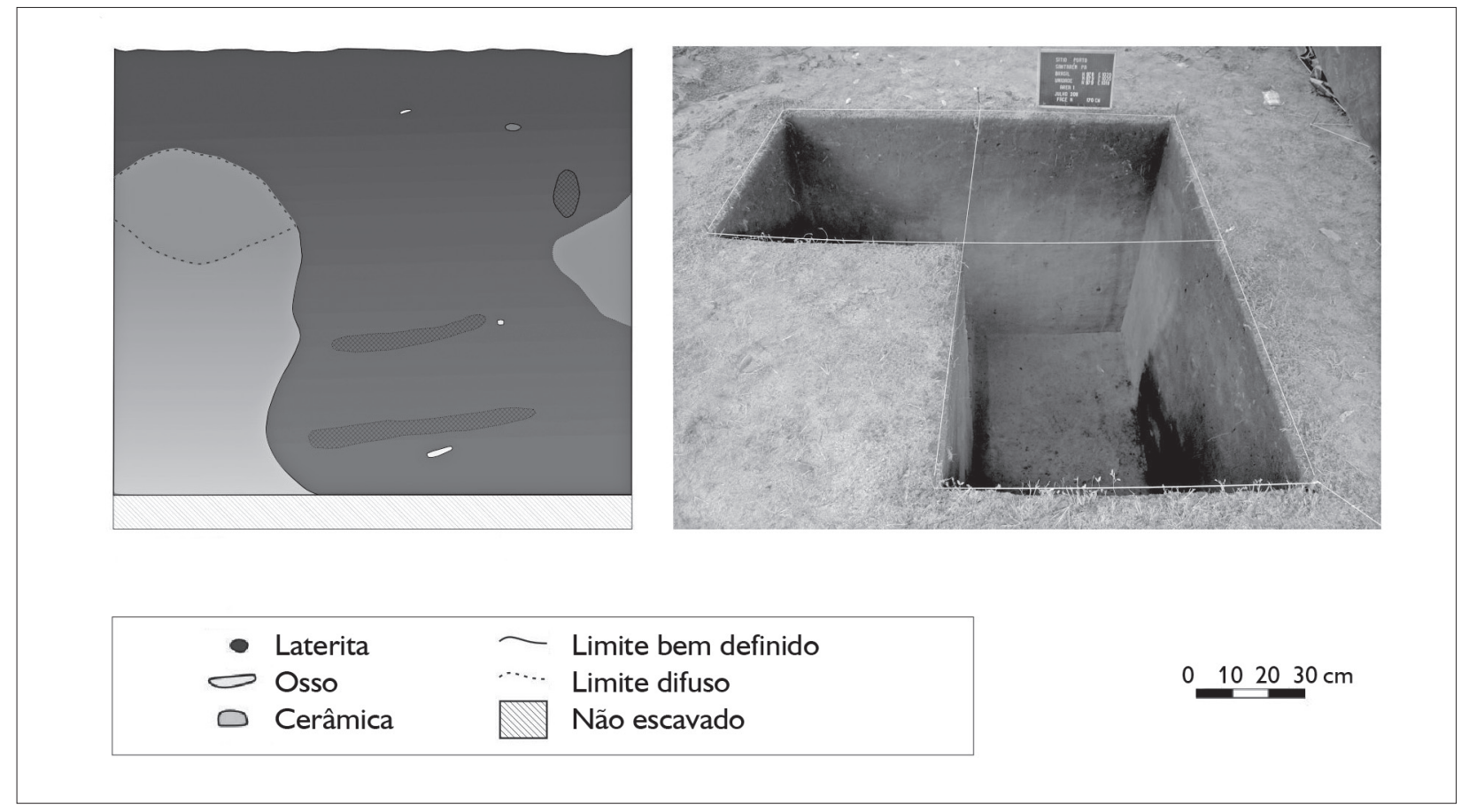

Figura 6. Desenho e foto do perfil leste da unidade 6 - N978 E1020, N979 E1020, também em forma de vale com descontinuidade, evidenciada na Figura 4.

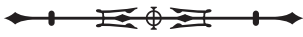


A unidade 6 - N979 E1029 foi escavada sobre a anomalia de GPR caracterizada por descontinuidade, evidenciada na linha 60, entre as posições 23 e 24 m (Figura 7). Essa unidade apresentou uma urna cerâmica inteira depositada em área habitacional, sem outros acompanhamentos (Figura 8), fragmentada pela pressão de raízes e com sedimento no interior. Trata-se de uma pequena vasilha cerâmica de boca circular, formato esférico, achatada, com uma inflexão na parte mesial e base convexa, coberta por um fragmento cerâmico, tendo $15 \mathrm{~cm}$ de altura e $20 \mathrm{~cm}$ de diâmetro. Apresenta vestígios de banho vermelho e apenas um aplique circular abaixo da borda, com cerca de 1,5 cm de diâmetro. A escavação do interior da urna foi realizada em laboratório por Anne Rapp Py Daniel. Os resultados do trabalho não revelaram a presença de ossos inteiros ou fragmentados no interior do artefato. Apenas após o peneiramento do sedimento interno, foi possível identificar a presença de microfragmentos de ossos, o que reforça a hipótese de este artefato apresentar a função de urna funerária, possivelmente para abrigar ossos calcinados.

Quanto aos artefatos líticos, são um destaque nessa área do sítio do Porto (PA 00788), uma vez que, em toda extensão do terreno pesquisado, foram encontrados abundantes vestígios líticos, compostos basicamente por lascas pequenas e microlascas, que apareceram em grande densidade nos primeiros $30 \mathrm{~cm}$ da unidade 14 N105 E1020, N1016 E1020, escavada sobre a anomalia GPR, caracterizada por descontinuidade (Figuras 9 e 10). Além disso, estão presentes calibradores líticos e, por último, alguns poucos artefatos de pedra lascada. Artefatos de pedra polida são raros. Tais vestígios estão dispostos de forma generalizada nessa área do sítio do Porto, embora existam concentrações definidas, o que permite supor a existência de áreas de atividade específica de produção de artefatos líticos, conforme atesta a escavação da unidade anteriormente descrita.

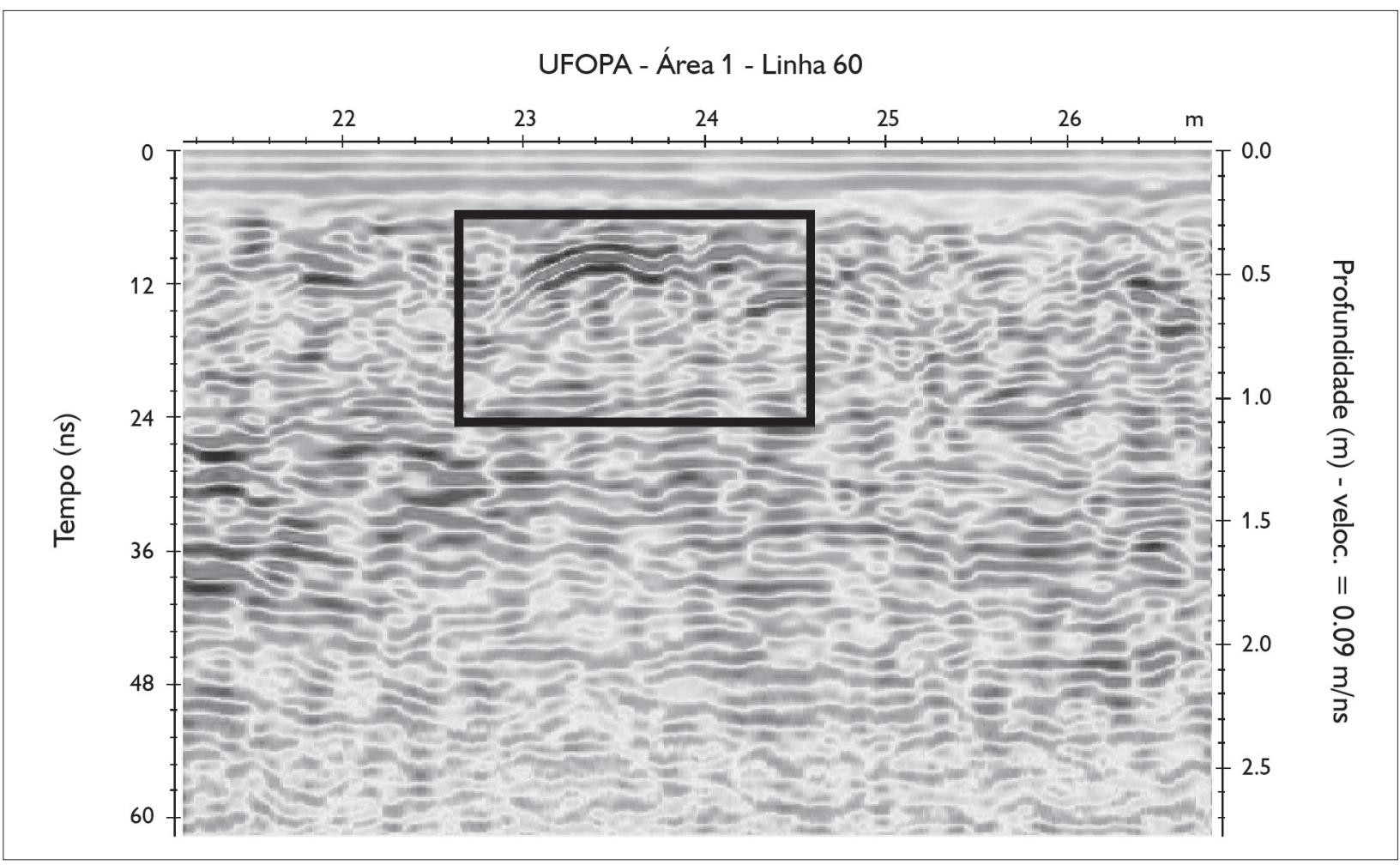

Figura 7. Imagem da linha 60, entre 23 e 24 m, com anomalia caracterizada por descontinuidade, destacada pelo retângulo.

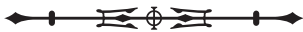




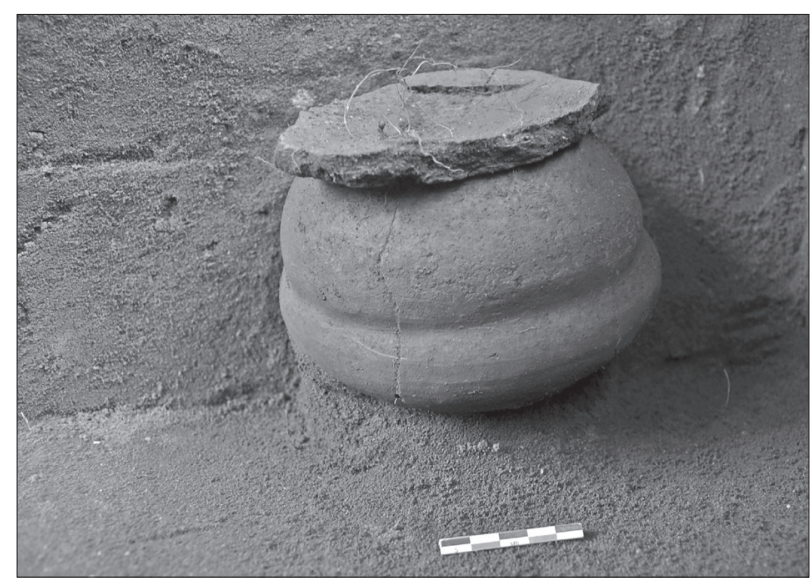

Figura 8. Foto da urna in situ escavada na unidade 6 - N979 E1029, a partir de indicação da anomalia de GPR, evidenciada na Figura 7.

Estes vestígios líticos indicam uma intensa produção de artefatos de pedra lascada, o que não é comum em outros sítios da região de Santarém. Apenas se tem conhecimento de indústrias de pedra lascada antigas associadas à ocupação paleoíndia na Caverna da Pedra Pintada, em Monte Alegre, Pará, correlacionadas a datações entre 11.100 anos e 10.000 anos A.P., de acordo com o exposto por Roosevelt e colaboradores (1996). Esta indústria era composta por artefatos como pontas de flecha retocadas e com pedúnculo, além de raspadores, juntamente com milhares de lascas.

No sítio do Porto, tais vestígios apontam para a presença de uma indústria com lascamento unipolar e bipolar, cuja matéria-prima básica é o silexito. Esta é formada basicamente por pequenas lascas. Aparecem ainda, em quantidade mais reduzida, artefatos retocados, prováveis furadores e raros raspadores. Outra indústria distinta encontrada no Campus Tapajós é a dos calibradores, que também são abundantes, tendo sido fabricados em arenito friável e materiais não friáveis, como a laterita. Os calibradores consistem em artefatos passivos, definidos como suportes, com marcas de utilização em forma de sulcos alongados (Prous, 1986/1990, p. 14), os quais foram constituídos pela ação de fricção de pontas de flecha ou de lança de madeira, a fim de afiná-las, formando sulcos na pedra. De acordo

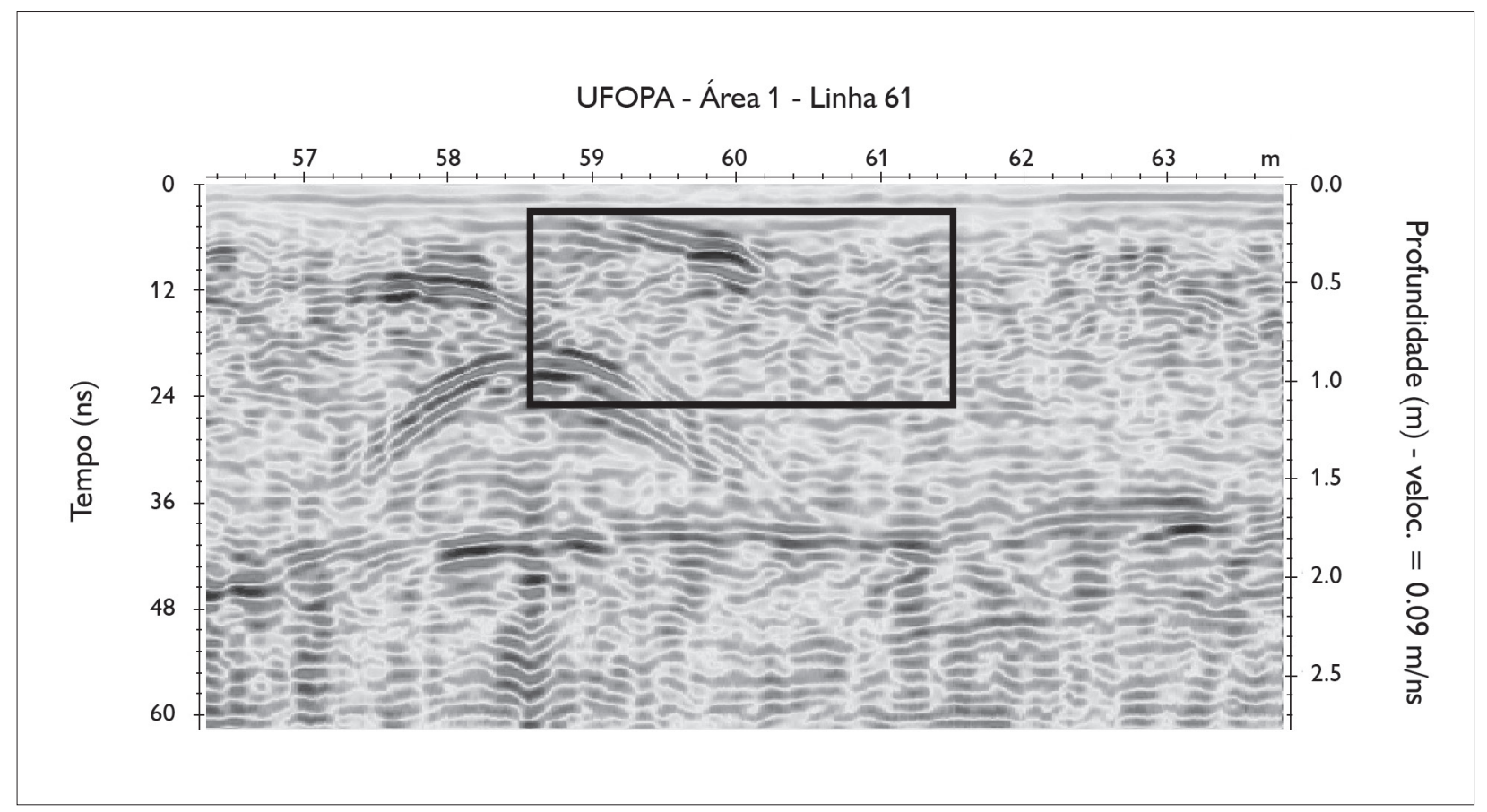

Figura 9. Imagem da linha 61, entre 59 e 61 m, com anomalia caracterizada por descontinuidade, destacada pelo retângulo.

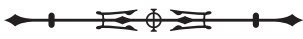



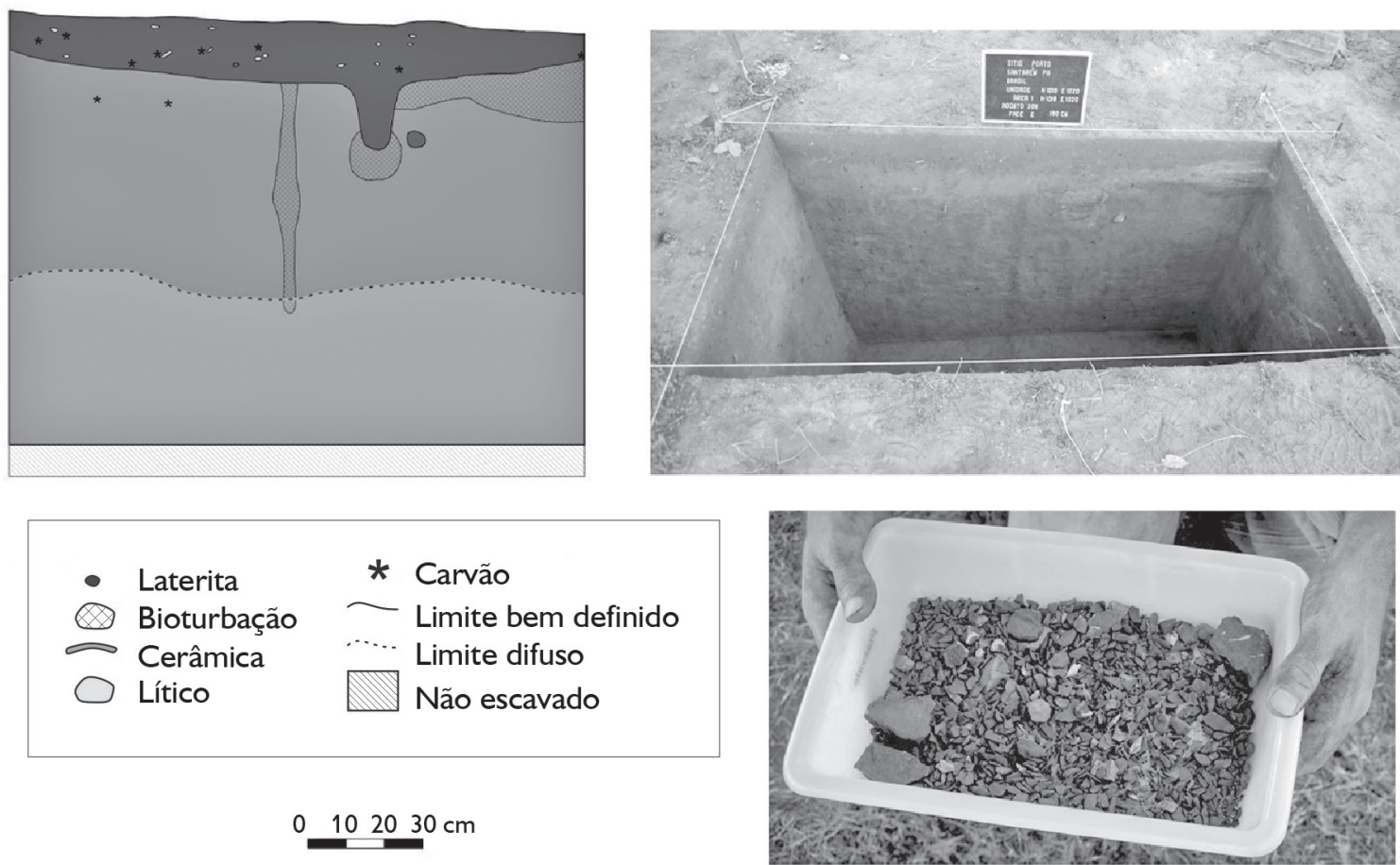

Figura 10. Desenho e foto do perfil face leste da unidade 14 - N105 E1020, N1016 E1020, com detalhe das lascas obtidas na escavação dos primeiros $10 \mathrm{~cm}$.

com Miller (1992, p. 336), essas lanças de madeira foram possivelmente utilizadas para pescar.

\section{OS PROCESSOS FORMATIVOS DO SÍTIO DO PORTO}

As contribuições de Schiffer (1972, 1975, 1976, 1983, 1987, 1989) sobre os processos formativos do registro arqueológico permitem saber que a proveniência dos artefatos no espaço intrassítio nem sempre está associada à sua localização de fato. Os comportamentos relacionados à organização social, ao padrão de subsistência e aos sistemas de assentamento não são os únicos responsáveis pelas propriedades observáveis em campo. Desde então, a variabilidade do registro arqueológico tem sido compreendida a partir de diferentes processos culturais e naturais, que modificam os materiais e a sua configuração. Processos naturais podem estar relacionados a diversos fatores, entre eles a bioturbação, causada por insetos e outros animais, documentada durante as escavações no sítio do Porto (Figura 11).

Alguns processos culturais também foram reconhecidos nas escavações do sítio do Porto (PA 00788).

O primeiro deles consiste em contextos secundários de agregação, que resultaram na deposição de refugo (Lamotta e Schiffer, 1999) e dizem respeito a atividades de limpeza da aldeia, as quais, no sítio do Porto (PA 00788), reuniram fragmentos de artefatos cerâmicos de tamanho reduzido, possivelmente resultantes do pisoteamento em solos de habitação, e ainda carvão e ossos de animais, em feições intencionalmente cavadas para este fim. São as lixeiras associadas às unidades 2 - N1021 E1020, N1022 E1020 e 6 - N978 E1020, N979 E1020. Uma vez que estas lixeiras também correspondem às maiores densidades artefatuais verificadas no sítio, é possível supor a repetição

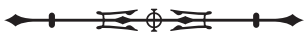




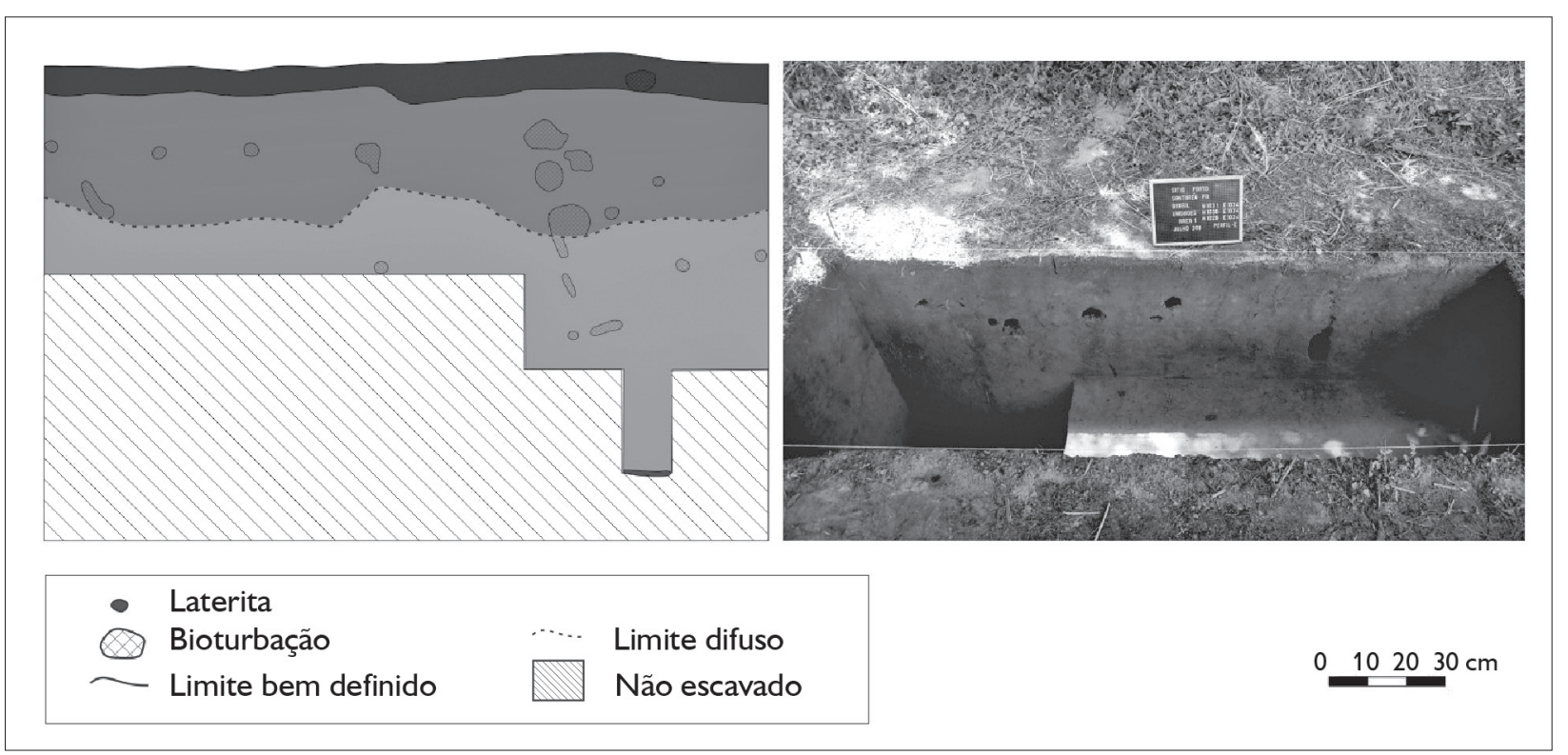

Figura 11. Desenho do perfil face oeste e foto do perfil face leste da unidade 1 - N1029 E1034, N1030 E1034, N1031 E1034, escavada a partir de indicação de anomalia GPR, associada à bioturbação.

dos comportamentos de limpeza e transporte (Schiffer, 1975, 1987, p. 17-18).

No sítio do Porto (PA 00788), Roosevelt (1999, 2009) e colaboradores (Quinn, 2004), bem como Gomes (2010)4, no sítio Aldeia (PA 01037), documentaram a existência dos bolsões cerimoniais, estruturas intencionalmente cavadas, destinadas a abrigar artefatos que foram usados durante rituais coletivos e depois descartados com sinais aparentes de quebra proposital. Esses bolsões foram interpretados como contextos de retenção, nos quais artefatos portadores de capacidade negativa, suscetíveis a produzir doenças e outros malefícios, foram isolados do contato com os indivíduos, conforme ocorre em diversos contextos etnográficos (Gomes, 2010, 2012).

Os bolsões são distintos das lixeiras anteriormente descritas, inicialmente a partir do seu conteúdo. Enquanto as lixeiras reúnem lixo comum, com exceção de pequenas estatuetas que parecem ter um uso associado ao espaço doméstico, os bolsões contêm apenas artefatos cerimoniais, tais como vasos de cariátides, de gargalo, de efígie de onça com pintura policrômica, entre outros, e, eventualmente, ossos de animais, indicando consumo de alimentos durante as cerimônias coletivas Gomes (2010)5. Por outro lado, o tamanho destas estruturas rituais, cujo diâmetro varia entre 0,50 m e 0,80 m, difere das lixeiras comuns do sítio do Porto, com diâmetro de 1,50 m, chegando a mais de $2 \mathrm{~m}$.

Já os padrões identificados nas escavações da unidade 14 - N105 E1020, N1016 E1020 parecem corresponder a contextos de deposição primária, que reuniram, no local, lascas e microlascas resultantes do processo de produção de artefatos líticos. Nesse sentido, eles constituem vestígios associados a áreas de atividades. Embora pequenas lascas estejam dispersas por todo o assentamento, nesta área a escavação da unidade demonstrou um aumento da

${ }^{4}$ Ver também GOMES, Denise Maria Cavalcante. Identificação de sítios arqueológicos da cultura Santarém na área central da cidade de Santarém, PA. Relatório Final apresentado ao Instituto do Patrimônio Histórico e Artístico Nacional (IPHAN). São Paulo, 2006.

5 Ver também GOMES, Denise Maria Cavalcante. Identificação de sítios arqueológicos da cultura Santarém na área central da cidade de Santarém, PA. Relatório Final apresentado ao Instituto do Patrimônio Histórico e Artístico Nacional (IPHAN). São Paulo, 2006.

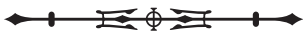


densidade artefatual não registrado em outros locais, o que confirma a hipótese de área de atividade. Conforme alerta Schiffer (1983, p. 685), a quantidade ou densidade de artefatos representa uma importante característica dos processos formativos de um assentamento.

Outra área de atividade foi detectada a partir da escavação da unidade 6 - N979 E1029, associada a um possível contexto funerário. Neste local, foi encontrada uma pequena vasilha coberta por um fragmento cerâmico, provavelmente contendo ossos calcinados, ainda que somente microfragmentos tenham sido identificados no sedimento interno, o que parece sugerir a existência de dupla inumação. Chaumeil (2007, p. 250) fornece mais informações a este respeito, ao se referir à prática etnográfica de reenterrar os ossos inteiros ou as cinzas em urnas funerárias menores ou em cestos, típica dos Arawak das Antilhas, do Orinoco e do sul do Amazonas.

Entretanto, a proximidade da unidade 6 - N978 E1020, N979 E1020, onde foi evidenciada uma lixeira, não deixa dúvidas de que este é um espaço localizado nos arredores de unidades residenciais, e não uma área especial da aldeia, destinada apenas a atividades funerárias. Este padrão contrasta com as descrições etnohistóricas, que apontam a ocorrência de cerimônias de endo-canibalismo na região de Santarém, envolvendo o consumo de cinzas dos ossos calcinados, misturadas a bebidas (Heriarte, 1874, p. 36-37; Nimuendajú, 1949), bem como de mumificação (Bettendorf, 1910; Daniel, 1976), sugerindo que a variabilidade dos contextos funerários associados à cultura Santarém possivelmente está ligada a questões de hierarquia social.

\section{CONSIDERAÇÕES FINAIS}

A partir das anomalias evidenciadas pelo GPR, foram recuperadas diferentes feições, artefatos arqueológicos, áreas de atividade de produção artefatual e um contexto funerário no sítio do Porto (PA 00788), relacionados à fase tardia da cultura Santarém (1000-1600 A.D.). Na pesquisa, foram revelados vestígios líticos e cerâmicos em um solo de terra preta antropogênica, que sugerem uma ocupação contínua. A maioria dos artefatos arqueológicos foi encontrada nas escavações realizadas sobre o padrão anômalo que envolve descontinuidades laterais nos registros do GPR. Apesar de diversas anomalias identificadas nos registros do GPR não terem sido causadas por feições ou artefatos relacionados com a ocupação pretérita, pode-se considerar que a metodologia geofísica foi empregada com sucesso e que deve ser usada em outras áreas do sítio.

O que merece destaque é o fato de que as escavações arqueológicas possibilitaram a geração de conhecimentos adicionais sobre essa cultura, especialmente sobre os contextos domésticos e padrões deposicionais relativos a comportamentos de cuidado e limpeza da aldeia, à produção de artefatos líticos lascados e calibradores e às práticas funerárias. Nesse sentido, o teste de anomalias geofísicas foi de fundamental importância. Além disso, as teorias existentes sobre os processos formativos do registro arqueológico mais uma vez demonstraram que estes transformam a cultura material em termos formais, espaciais e quantitativos.

\section{AGRADECIMENTOS}

As pesquisas reportadas neste artigo foram coordenadas por Denise Gomes e desenvolvidas com o apoio da UFOPA e em bases colaborativas com a Universidade Federal do Pará (UFPA). Os autores agradecem o incentivo do professor Dr. José Seixas Lourenço, reitor da UFOPA. Agradecem ainda a participação dos professores Dr. Claide de Paula Moraes e M.Sc. Anne Rapp Py Daniel, bem como dos alunos Ana Betânia de Sousa Pimentel, Andrei Nunes Figueira, Beatriz Martins Moura, Edvaldo Pereira, Graciela Melo Serique, Keiliane de Lima Bandeira, Miguel Ângelo de Sá Nieto, que durante o mês de julho de 2011 auxiliaram como voluntários nos trabalhos de campo. Os autores estendem seus agradecimentos ao geólogo Livaldo Santos (UFOPA) e ao técnico Paulo Magalhães (UFPA), pelo auxílio prestado na 
preparação da área para o levantamento e na coleta dos dados geofísicos. As atividades de topografia, preparação de campo para o levantamento geofísico e produção de mapas foram realizadas pelo engenheiro agrimensor Wagner Luís Gonçalves Silva, da UFOPA, a quem somos gratos. Edvaldo Pereira também colaborou na documentação fotográfica das escavações, e o professor Claide de Paula Moraes foi responsável pela digitalização de perfis de escavação.

\section{REFERÊNCIAS}

ACUÑA, Cristobal de. Novo descobrimento do grande rio das Amazonas. In: CARVAJAL, Gaspar; ROJAS, Alonso; ACUÑA, Cristobal de (Eds.). Descobrimentos do Rio das Amazonas. São Paulo: Companhia Editora Nacional, 1941. p. 12-294.

ALVES, José Jerônimo de Alencar. Métodos geofísicos aplicados à arqueologia no estado do Pará. 1979. 55 f. Dissertação (Mestrado em Geofísica) - Universidade Federal do Pará, Belém, 1979.

ALVES, José Jerônimo de Alencar; LOURENÇO, José Seixas. Métodos geofísicos aplicados à arqueologia no estado do Pará. Boletim do Museu Paraense Emílio Goeldi, Série Geologia, v. 26, p. 1-52, 1981.

BARATA, Frederico. Uma análise estilística da cerâmica de Santarém. Cultura, São Paulo, v. 5, p. 185-205, 1953a.

BARATA, Frederico. A arte oleira dos Tapajó III. Alguns elementos para a tipologia de Santarém. Belém: Instituto de Antropologia e Etnologia do Pará, 1953b.

BARATA, Frederico. A arte oleira dos Tapajó II. Os cachimbos de Santarém. Revista do Museu Paulista, Nova Série, São Paulo, n. 5, p. 183-198, 1951.

BARATA, Frederico. A arte oleira dos Tapajó I. Considerações sobre a cerâmica e dois tipos de vasos característicos. Belém: Instituto de Antropologia e Etnologia do Pará, 1950.

BARBOSA RODRIGUES, João. Exploração e estudo do Valle do Amazonas e Rio Tapajós. Rio de Janeiro: Tipografia Nacional, 1875.

BETTENDORF, João Felipe. Chronica da missão dos padres da Companhia de Jesus no Estado do Maranhão. Revista do Instituto Histórico e Geográfico Brasileiro, v. 72, n. 1, p. 1-679, 1910.

CARVAJAL, Gaspar de. Relação do novo descobrimento do famoso Rio Grande que descobriu por grande ventura o Capitão Francisco de Orellana. In: CARVAJAL, Gaspar; ROJAS, Alonso; ACUÑA, Cristobal de (Eds.). Descobrimentos do Rio das Amazonas. São Paulo: Companhia Editora Nacional, 1941. p. 11-79.
CHAUMEIL, Jean-Pierre. Bones, flutes and dead: memory and funerary treatments in Amazonia. In: FAUSTO, Carlos; HECKENBERGER, Michael (Eds.). Time and memory in indigenous Amazonia. Gainesville: University Press of Florida, 2007. p. 243-283.

CORRÊA, Conceição Gentil. Estatuetas de cerâmica na cultura Santarém: classificação e catálogo das coleções do Museu Goeldi. Publicações Avulsas do Museu Paraense Emílio Goeldi, Belém, n. 4, p. 3-88, 1965.

DANIEL, João. Tesouro descoberto no Rio Amazonas. Rio de Janeiro: Biblioteca Nacional, 1976.

GOMES, Denise Maria Cavalcante. O perspectivismo ameríndio e a ideia de uma estética americana. Boletim do Museu Paraense Emílio Goeldi. Ciências Humanas, v. 7, n. 1, p. 133-159, 2012.

GOMES, Denise Maria Cavalcante. Os contextos e os significados da arte cerâmica dos Tapajó. In: PEREIRA, E.; GUAPINDAIA, V. L. C. (Orgs.). Arqueologia amazônica. Belém: Museu Paraense Emílio Goeldi/SECULT/IPHAN, 2010. v. 1, p. 213-234.

GOMES, Denise Maria Cavalcante. The diversity of social forms in Pre-Colonial Amazonia. Revista de Arqueologia Americana, v. 25, p. 189-225, 2007.

GOMES, Denise Maria Cavalcante. A cerâmica Santarém e seus símbolos. In: CALLIA, M.; OLIVEIRA, M. F. (Eds.). Terra Brasilis: préhistória e arqueologia da psique. São Paulo: Paulus, 2006. p. 49-72.

GOMES, Denise Maria Cavalcante. Cerâmica arqueológica da Amazônia: vasilhas da coleção Tapajônica do MAE-USP. São Paulo: EDUSP/FAPESP/Imprensa Oficial, 2002.

GOMES, Denise Maria Cavalcante. Santarém: symbolism and power in the tropical forest. In: MCEWAN, Collin; BARRETO, Cristiana; NEVES, Eduardo (Eds.). The unknown Amazon. London: The British Museum Press, 2001. p. 134-155.

GUAPINDAIA, Vera Lúcia Calandrini. Fontes históricas e arqueológicas sobre os Tapajó: a coleção Frederico Barata do Museu Paraense Emílio Goeldi. 1993. Dissertação (Mestrado em História) Universidade Federal de Pernambuco, Recife, 1993.

HECKENBERGER, Michael; NEVES, Eduardo Góes. Amazonian Archaeology. Annual Review of Anthropology, v. 38 , p. 251-266, 2009 .

HERIARTE, Maurício de. Descriçam do Estado do Maranham, Para, Corupa, Rio das Amazonas. Viena: Carlos Gerold, 1874.

LAMOTTA, V.; SCHIFFER, M. Formation processes of house floor assemblages. In: ALLISON, P. M. (Ed.). The archaeology of household activities. London: Routledge, 1999. p. 19-29.

LINNÉ, Sigvald. Les recherches archéologiques de Nimuendajú au Brésil. Journal de La Societé des Americanistes de Paris, v. 20, p. 71-91, 1928.

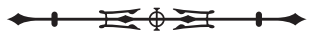


LUIZ, José Gouvêa. Metodologias geofísicas aplicadas à prospecção arqueológica no estado do Pará. In: PEREIRA, E.; GUAPINDAIA, V. L. C. (Orgs.). Arqueologia Amazônica. Belém: Museu Paraense Emílio Goeldi/SECULT/IPHAN, 2010. v. 2, p. 949-966.

MACDONALD, Regina. The order of the things: an analysis of ceramics from Santarém, Brazil. Journal of the Steward Anthropological Society, v. 4, n. 1, p. 39-55, 1972.

MÉTRAUX, Alfred. Contribution a l'etude de l'Archéologie du cours supérieur et moyen de l'Amazone. Revista del Museu de La Plata, v. 32, p. 145-185, 1930.

MILLER, Eurico. Adaptação agrícola pré-histórica no alto rio Madeira. In: MEGGERS, Betty (Ed.). Pré-História americana Washington: Taraxacum, 1992. p. 219-229.

NIMUENDAJU', Curt. Traces of Indian habitation on the Lower Amazon. In: STENBORG, Per (Ed.). In Pursuit of a Past Amazon. Archaeological researches in the Brazilian Guyana and in the Amazon region. Göteborg: Museum of World Culture, 2004. (Ethnological Studies, 45). p. 127-146.

NIMUENDAJú, Curt. Os Tapajó. Boletim do Museu Paraense Emílio Goeldi, série Antropologia, v. 10, p. 93-106, 1949.

NORDENSKIÖLD, Erland. L'Archéologie du bassin de l'Amazone. Paris: Les Éditions G. Van Oest, 1930.

PALMATARY, Hellen. The archaeology of the lower Tapajós valley, Brazil. Philadelphia: American Philosophical Society, 1960.

PALMATARY, Hellen. Tapajó Pottery. Etnologiska Studier, n. 8, p. 1-136, 1939.

PROUS, André. Os artefatos líticos: elementos descritivos classificatórios. Arquivos do Museu de História Natural, Belo Horizonte, v. 11, n. 1, p. 1-88, 1986/1990.

QUINN, Ellen. Excavating "Tapajó” ceramics at Santarém: their age and archaeological context. 2004. Tese (Doutorado em Antropologia) - University of Illinois at Chicago, Chicago, 2004.

ROJAS, Afonso de. Descobrimento do Rio das Amazonas e suas dilatadas províncias. In: CARVAJAL, Gaspar; ROJAS, Alonso; ACUÑA, Cristobal de (Eds.). Descobrimentos do Rio das Amazonas. São Paulo: Companhia Editora Nacional, 1941. p. 81-124.

ROOSEVELT, Anna Curtennius. A historical memoir of archaeological research in Brazil (1981-2007). Boletim do Museu Paraense Emílio Goeldi. Ciências Humanas, v. 4, n. 1, p. 155170, 2009
ROOSEVELT, Anna Curtennius. Geophysical archaeology in the lower Amazon: a research strategy. In: WISWMAN, J.; EL-BAZ, Farouk (Eds.). Remote sensing in archaeology. New York: Springer, 2007. p. $443-475$

ROOSEVELT, Anna Curtennius. Complex polities in the ancient tropical world. Arlington: American Anthropological Association, 1999. p. 13-33.

ROOSEVELT, Anna Curtennius. Moundbuilders of the Amazon: geophysical and archaeology in the lower Amazon. New York: Academic Press, 1991

ROOSEVELT, Anna Curtennius. Interpreting certain female images in Prehistoric Art. In: MILLER, V. E. (Ed.). The role of gender in Pre-Columbian Art and Architecture. Labham: University Press of America, 1988. p. 1-34.

ROOSEVELT, A. C.; LIMA DA COSTA, M.; MACHADO, C. L.; MICHAB, M.; MERCIER, N.; VALLADAS, H.; FEATHERS, J.; BARNETT, W.; IMAZIO DA SILVEIRA, M.; HENDERSON, A.; SILVA, J.; CHERNOFF, B.; REESE, D. S.; HOLMAN, J. A.; TOTH, N.; SCHICK, K. Paleoindian cave dwellers in the Amazon: the peopling of America. Science, v. 272, n. 5260, p. 372-384, 1996.

SCHIFFER, Michael. Formation processes of Broken K. Pueblo: some hypotheses. In: LEONARD, R. D.; JONES, G. T. (Eds.). Quantifying diversity in Archaeology. Cambridge: Cambridge University Press, 1989. p. 37-58.

SCHIFFER, Michael. Formation processes of the archaeological record. Albuquerque: University of New Mexico Press, 1987.

SCHIFFER, Michael. Toward the identification of formation processes. American Antiquity, v. 48, n. 4, p. 675-706, 1983.

SCHIFFER, Michael. Behavioral Archaeology. New York: Academic Press, 1976.

SCHIFFER, Michael. Archaeology as behavioral science. American Anthropologist, v. 74, n. 4, p. 836-848, 1975.

SCHIFFER, Michael. Archaeological context and systemic context. American Antiquity, v. 37, n. 2, p. 156-165, 1972

STENBORG, Per (Ed.). In Pursuit of a Past Amazon. Archaeological researches in the Brazilian Guyana and in the Amazon region. Göteborg: Museum of World Culture, 2004. (Ethnological Studies, 45). 